\title{
Self-directed, problem-based learning for undergraduate psychiatry
}

\author{
Elspeth Guthrie \& Paul O'Neill
}

Medical undergraduate training is currently going through a momentous period of change (Tosteson, 1990). New methods of learning and evaluation are being introduced which will radically alter medical training over the next few years. These changes are in part a response to the way medicine itself is being transformed. Medical educators can no longer hope to equip medical students, upon qualification, with enough basic knowledge and skills to last them throughout their medical careers. Today's students are embarking upon a process of learning which will continue throughout their medical lives. Medical practice will be very different, when today's students become tomorrow's hospital consultants and general practitioners.

In 1993, the General Medical Council (GMC) published a report entitled Tomorrow's Doctors. In this document, traditional methods of medical undergraduate teaching were criticised. The GMC was particularly concerned about the detrimental effects of lecture-based courses on the development of students' abilities to learn in a self-directed and independent manner. The report suggested that, on traditional, lecture-based courses, students were expected to learn too much information - much of which was either unnecessary or would be out of date by the time they qualified. It suggested that this emphasis upon rote learning actually prevented students from assimilating information in a meaningful way, and extinguished an interest and desire to learn.

Medical schools in the UK have had to respond to the GMC's concerns and many are introducing new courses based around the concept of 'problem-based learning' (PBL). In this new method, students are encouraged to be active participants in the learning process and to take responsibility for educating themselves, as opposed to the traditional system where students are deemed to be passive recipients of learned knowledge.

In this article we will describe the key features and components of PBL. We will describe how it is being developed and implemented on medical courses, and will use examples from the undergraduate medical curriculum at Manchester University, which was the first medical school in the UK to introduce an entirely PBL course. We will make particular reference to how psychological issues and psychiatry can be more easily integrated into medical learning within the new format.

\section{Historical development}

Problem-based learning was first employed in medical undergraduate training in the mid-1960s at the McMaster University in Ontario, Canada. Ten years later, the University of Limburg (now re-named the University of Maastricht) established a medical school based upon the model developed at McMaster. Much of the subsequent development of PBL has been driven from innovative teaching methods implemented at Maastricht. Interest in PBL courses has spread to other parts of North America and to Australia in particular, at Harvard Medical School and Newcastle University in New South Wales. In the UK, Manchester University now has an integrated core course from years 1 to 4 based on using PBL (David \& Patel, 1995), and many other UK medical schools (notably Liverpool and Glasgow) are implementing PBL approaches.

Elspeth Guthrie is Senior Lecturer in Liaison Psychiatry at Manchester University (School of Psychiatry and Behavioural Sciences, Rawnsley Building, Manchester Royal Infirmary, Oxford Road, Manchester M13 9WL) and a member of the Curriculum Development Group for the undergraduate medical course. Paul O'Neill is Senior Lecturer in Geriatric Medicine at Manchester University and Associate Dean of Undergraduate Medical Studies. 


\section{Principal components of problem-based learning}

Individuals' learning is enhanced if they are able to attach new pieces of information on to an existing foundation of knowledge. Learning is facilitated by interest and motivation, and by a process of assimilation, so that work is done by the learner to actively integrate the new information into a logical and cohesive framework. This process is the exact antithesis of rote learning, where information is laid down separately in the mind and can then only be regurgitated in a parrot-like fashion, without any sense of integration or understanding.

Problem-based learning is designed to maximise the potential for learning. The process follows identifiable steps which are specifically designed to stimulate the acquisition of knowledge in an assimilated and integrated format. In Manchester, students are presented with so-called stimulus or trigger material in the form of a person-based problem. An example of a case problem in the preclinical years is as follows:

A university student is stabbed in the chest when he discovers burglars in his flat. He is assessed in Casualty and it is found that he has evidence of a tension pneumothorax with surgical emphysema. A chest drain is inserted with drainage. The pneumothorax closes spontaneously. He is also subsequently seen by the university counselling service because of the psychological disturbance resulting from the assault.

The nature of the stimulus material is important. The shorter the case, the more likely it is to stimulate thought, discussion and problem-solving. A good case is one which students find stimulating, relevant to the particular stage of the course, and which leads them to focus upon the areas of learning that the case writers had hoped would be highlighted by the case material. In the above example, the case is meant to stimulate learning objectives in relation to: pneumothorax; trauma of the chest and abdomen; breathlessness; shock; and psychological factors such as affective disorders and post-traumatic stress disorder.

\section{Tutorial groups and contextual learning}

In Manchester, the process of working through a problem has been divided into eight stages. This is called the 'eight-step' tutorial process and was adapted from a 'seven-step' process developed at Maastricht. The stages are shown in Box 1.
The cycle is very simple. Eight students meet as a group with a tutor to discuss a problem using steps 1-5 (Box 1). At the end of this one-hour tutorial, all students go away with the same core learning goals (although some students may also have less central tasks that they will undertake for the group). In step 6 , the students use a variety of learning resources to try to meet the core goals. These resources may include leactures (giving overviews and explanations of difficult concepts), workshops, seminars, books, articles and web-pages. In Manchester, for years 3 and 4, we have extended this to include clinical resources. So students may seek out patients (in hospital or at home) with similar clinical problems and talk to clinical staff (doctors and professionals allied to medicine) involved in their care. In this way, students will start to generalise from a particular case about a patient with depressive illness to an understanding about how depression manifests in different people in a variety of ways.

In steps 7 and 8, the students meet one week later for 90 minutes to discuss what they have learnt. The

Box 1. The eight-step tutorial process

During the first tutorial

Clarify the terms and concepts in the problem unfamiliar to you

List the phenomena to be explained

Try to produce as many different explanations for the phenomena that you can think of. Use your experience (including clinical) and common sense

Arrange the explanations proposed: try to produce a coherent description of the processes that you think underlie the phenomena

Formulate the learning goals (what you need to find out) and what clinical experience you should gain

Self-study

Attempt to fill gaps in your knowledge and understanding by using any resources available to you (and record these)

At subsequent tutorials

Share your findings (and the resources used) with your group and try to integrate these into a comprehensive explanation for the phenomena

Discuss how your findings help to explain the clinical problems experienced by the patients you have seen 
critical aspects are that students compare their understanding of the problem and try to reconcile any differences (dealing with any uncertainty). They discuss how similar the problem is to the patients they have seen. A further important element is becoming aware, through their fellow students, of the different learning and clinical resources available and their value (learning how to learn).

Students take it in turns to act as chair and scribe for the group. The role of the tutor is to ensure that the group process runs smoothly and that the group discusses the problem in sufficient depth. A principal means of doing this is by the tutor using his or her knowledge of the problem to ask probing questions. The tutor may also help the group in becoming aware of, and accessing, learning resources, particularly clinical experience. In Manchester, the tutors in years 3 and 4 are mostly National Health Service consultants.

As students acquire new information in relation to case material, they learn about it in the context of a clinical problem (e.g. they associate polycystic kidneys with the case of Mrs B). This means they are more likely to recall and use this information when they are actually working in a clinical situation or faced with a clinical problem in an examination.

\section{An integrated course}

The PBL method helps to provide a more integrated approach to medical learning. Cases are based upon 'real people' who can have physical, psychological and social problems, and often have a mix all three. Completely different disorders can occur in the same case. For example, a case could involve a patient with schizophrenia who jumps out of a window sustaining fractures to both legs. Students would have to consider both the psychological and the physical aspects of this case together.

\section{Emphasis on skills and attitudes}

Problem-based learning can also emphasise to students the importance and use of clinical skills that they need to acquire. In the later years of the course, specific triggers are written into cases in the knowledge that they will stimulate students to find out about these skills and, hopefully, acquire them. Ward-based clinical attachments continue alongside the PBL sessions, so students can use their clinical attachments to practise skills which are highlighted in the cases.

Problems involving communication between doctors, patients and their relatives are a feature of several cases, as are ethical dilemmas or attitudinal problems. These themes run throughout the course.

\section{Psychiatry and problem-based learning}

In many medical schools, students learn about psychiatry during one clinical attachment in the fourth or final year. This has encouraged students to learn about mental health and illness in a compartmentalised way, which means that students are often unable to use the skills and knowledge that they have acquired during their psychiatry attachment in other settings. In Manchester, students learn about the main aspects of mental illness in year 4 during a module entitled 'Cognitions, special senses and locomotion'. This module draws together conditions within medicine which require long-term support, treatment and rehabilitation. The effects upon patients and their carers of chronic and disabling physical and mental disorders are studied. Several of the cases focus upon or include aspects of mental illness, and they are summarised in Table 1. While working through the cases, the students have clinical attachments in psychiatry, and spend one day per week in primary care.

A major problem of traditional psychiatric teaching at undergraduate level has been that it focuses upon severe mental illness and in-patient psychiatry without preparing students for the more common psychological disorders (such as somatisation, acute confusional states, abnormal bereavement reactions and psychological reactions to physical illness), which are seen routinely in the general hospital setting and primary care. As most medical students are not going to become psychiatrists, it is these common psychological problems that they will have to recognise, diagnose and treat, when they become doctors. It is often these very disorders, however, that they are most illequipped to treat (Williams et al, 1997) and that are often neglected by traditional courses (Sharpe et al, 1996).

We at Manchester think that PBL is a good method for helping students to understand the common psychological problems in medicine, which are often the result of complex interactions between mind and body. In the first two years of the course, students are given several cases that include physical and psychological issues and that highlight the importance of understanding psychological reactions in relation to disease processes. A summary of these cases is shown in Table 2.

When students progress to the clinical environment in year 3 and are attached to medical firms, students learn how to carry out a mental state examination, and how to recognise and treat depression in the context of serious physical disease. 


\section{Table 1. Case-problems in year + which include psychiatric components}

\section{Case title \\ Thanks for the Memory}

The Worst of Times

Treoor and the

Teleoision

Growing Up

Crash

Swings and Roundabouts
Key problem areas

Dementia
Degenerative CNS
$\quad$ disease
Hearing loss
Hypothermia
Falls
Visual loss

Self-poisoning Affective disorders Inflammatory arthritis Substance misuse Acid base disturbance

Schizophrenia Substance misuse Confusion
Summary of the case

The case focuses on an 86-year-old widow living alone who is referred to an old age psychiatrist. On the domiciliary visit, there is evidence of self-neglect and on examination, marked cognitive impairment is found. She is also visually impaired and deaf. A diagnosis of dementia is made and the case describes the various agencies involved in her care.

A 35-year-old woman is brought to A\&E with evidence of severe salicylate poisoning. It transpires that she has systemic lupus erythematosus (SLE) and has been receiving treatment for this. The students discuss whether the patients is depressed because of her severe illness or whether her mental state is a manifestation of SLE.

The problem describes the onset of schizophrenia in a university student. The importance of prior personality and upbringing is highlighted. The patient is managed jointly by the GP and the consultant psychiatrist. At one stage he has to be detained under the Mental Health Act. Some of the side-effects of treatment are highlighted.

The problem is presented from the point of view of the GP. Getrude is the 14-year-old daughter of Mrs Angst. She has taken an overdose of paracetamol and vodka. The problem covers difficulties with body image and weight gain, together with school bullying and sexual activity in teenagers.

A young man is brought to A\&E because of multiple injuries following a road traffic accident. The initial assessment and management of limb fractures are given. It also becomes clear that the crash was an attempted suicide because of depression.

Suicide and self-harm Depression

Aggression/violence

Hip disorders

Affective disorders

Depression

Poisoning

Substance misuse

Aggression/violence
A 25-year-old woman presents with an episode of hypomania. Drug misuse is also suspected. The patient has a previous episode of depression following a termination of pregnancy. She is treated with haloperidol and lithium which causes some toxic effects.
They also learn about somatisation and the way that over-investigation and referral can make the condition worse. Table 3 shows the relevant cases that trigger discussion about these conditions. They are encouraged to discuss the cases with their community tutors (general practitioners), to whom they are attached for one day per week, and this helps to emphasise the common nature of these problems and the importance of early detection and treatment.

\section{Empirical evidence to support problem-based learning}

There is still considerable debate about the value of PBL in comparison with traditional lecture-based courses (Albanese \& Mitchell, 1993; Berkson, 1993). 
lable 2. Case-problems that trigger parchological factors in the first two vears of the course

Case title

A Worrying Man

The Man with

Serious Indigestion

Problems

A Young Patient

with Heat

Intolerance

An Older Person

with Cold

Intolerance

A Suspicious Death

Patient whose Pen would not Keep Up with his Thoughts
Key problem areas

\author{
Abdominal pain \\ Anxiety/phobia \\ Vomiting loss
}

Disorders of the pancreas

Substance misuse

Tiredness

Malabsorption

Abdominal pain

Oedema

Weight loss

Loose stools

Thyroid disorders

Palpitations

Anxiety/phobia

Weight loss

Lump in neck

Disorders of muscle

\section{Thyroid disorders \\ Tiredness \\ Depression \\ Constipation \\ Weight gain}

\section{Chronic liver disease \\ Substance misuse \\ Confusion \\ Haematemesis}

Movement disorders

Degenerative

CNS disease

Depression

\section{Summary of the case}

A 31-year-old man has a generally anxious personality. $\mathrm{He}$ describes symptoms of a peptic ulcer and the diagnosis is confirmed by endoscopy. However, before he can start treatment his ulcer perforates and he develops an acute abdomen with shock.

A 40-year-old French immigrant is known to drink and smoke heavily. He presents to his GP with a six-year history of severe upper abdominal pain going through to his back.

\begin{abstract}
A 30-year-old woman presents with symptoms of thyrotoxicosis and a goitre. She is anxious. On examination she has symptoms of thyroid overactivity including a proximal myopathy.
\end{abstract}

A 79-year-old woman has had a sub-total thyroidectomy many years earlier. She has now developed symptoms and signs of hypothyroidism. The thyroid function tests confirms the diagnosis.
A 61-year-old man is found dead in a pool of blood and an autopsy report is presented. The history is of heavy longterm alcohol consumption with progressive evidence of cirrhosis and liver failure. He has died because of a haematemesis and subsequent aspiration.

A 70-year-old man lives in a residential home. For about 10 years he had noticed that his writing had become increasingly difficult.
Randomised controlled trials are difficult to undertake in the context of medical undergraduate training, and it is virtually impossible to exclude contamination effects occurring between different students on the same course, even if different methods of learning are employed for different groups. In most studies, therefore, different schools are compared or consecutive cohorts of students are studied - those who have experienced an old-style curriculum and those in receipt of a new method of learning.

One review (Vernon \& Blake, 1993) described five separate meta-analyses of 35 studies involving comparisons between PBL courses and traditional educational methods. The authors suggested that the results broadly support the superiority of the PBL approach over more traditional methods. Problem-based learning was found to be significantly superior with respect to students' attitudes and opinions about their courses, and measures of clinical performance. Traditional methods and PBL did not differ on miscellaneous tests of factual knowledge and tests of clinical knowledge.

There is some evidence that PBL enhances students' diagnostic skills. A Dutch study of three different medical schools, each with a different 


\section{Iable 3. Case-problem that trigger psvohological factors in vear 3 of the course}

\begin{tabular}{|c|c|}
\hline Case title & Key problem areas \\
\hline $\begin{array}{l}\text { The Heavy Drinker } \\
\text { with Abdominal Pain }\end{array}$ & $\begin{array}{l}\text { Peptic ulcer } \\
\text { Carcinoma of the stomach } \\
\text { Abdominal pain } \\
\text { Alcoholism }\end{array}$ \\
\hline $\begin{array}{l}\text { A Case of Abdominal } \\
\text { Pain }\end{array}$ & $\begin{array}{l}\text { Depression } \\
\text { Irritable bowel syndrome } \\
\text { Dysuria } \\
\text { Frequency of micturition }\end{array}$ \\
\hline It Wears You Down & $\begin{array}{l}\text { Chronic bronchitis and } \\
\text { emphysema } \\
\text { Depression } \\
\text { Respiratory tract infection }\end{array}$ \\
\hline $\begin{array}{l}\text { Accident and } \\
\text { Emergency }\end{array}$ & $\begin{array}{l}\text { Somatisation } \\
\text { Panic disorder } \\
\text { Chest pain }\end{array}$ \\
\hline
\end{tabular}

\section{Summary of the case}

A cigarette-smoking young male with a heavy alcohol intake develops abdominal pain. The pain described raises the possibility of peritonitis, pancreatitis or peptic ulcer disease. The examination demonstrates shock and features of a perforated oesophagus. The case goes on to describe a laparotomy with standard management.

The problem is presented using a sheaf of letters between the GP and hospital. The problem is about a 35-year-old woman with abdominal pain and a history consistent with depression. She is seen by number of specialists who do not recognise that she is depressed or the relationship between her pain and her mental state.
A 57-year-old woman presents with a one-week history of breathlessness, wheezing and coughing up green sputum. She has a long history of chronic bronchitis and emphysema. The patient is noticed to be withdrawn and depressed. Her physical function has deteriorated in the last six months although her respiratory tests have not changed. Her depression is understood in the context of a bereavement and a disabling chronic illness.

The problem is set out as a record sheet from the A\&E department. A 51-year-old woman has been a frequent attender at the department because of non-cardiac chest pain. This is associated with anxiety and over-concern about a strong family history of cardiac disease. method of teaching, suggested that students trained within either a problem-based framework, or on an integrated course, produced more accurate diagnoses than students trained using traditional methods (Schmidt et al, 1996).

In relation to psychiatry, a recent Canadian study compared the level of achievement on the Medical Council of Canada Qualifying Examination (Part I) of students in conventional and PBL curricula (Kaufman \& Mann, 1998). The authors found that the PBL students performed significantly better on the psychiatry component of the examination than the conventional class, and also did better in relation to preventive medicine and community health. No differences emerged in any of the other disciplines.

In the UK, Nottingham University has recently changed its method of teaching psychiatry to medical undergraduates. A much shorter problem-oriented course has replaced a traditional lecture-based course. Singh et al (1998) have evaluated the new module and found that it appears to be as effective in changing students' attitudes to psychiatry (making them more positive) as the former, much lengthier attachment, but achieved this is a shorter time period.

It is difficult to draw any firm conclusions from these findings, as it could be argued that the small advantages attributed to PBL could be a result of non-specific factors such as the drive and enthusiasm of teaching staff in relation to a new course. Problem-based learning, however, is popular with students and the change to the new course in Manchester has been warmly welcomed by the student body.

\section{Difficulties in implementation of problem-based learning}

It is difficult to make substantial changes to any large organisational system, and medical schools and teaching hospitals are no different. Problembased learning courses may be more labour- 
intensive than traditional lecture courses in terms of staff time, commitment and energy. Thus, medical teachers are being asked to allocate considerable amounts of their time for student teaching, when they are also feeling pressurised by additional clinical commitments, managerial responsibilities and research.

Those clinicians who become PBL tutors require training and have to learn new skills in order to run PBL groups. It is a considerable logistical exercise for any medical school to attempt to re-train its teaching staff and clinician teachers.

Problem-based learning courses also raise fears among many hospital clinicians who were trained using traditional methods. They fear that students will not be able to take responsibility for their own self-directed learning, as they are used to teaching medical students who have been conditioned to be passive and helpless and require 'spoon-feeding'.

\section{So why change?}

Both external reports (General Medical Council, 1993) and clinicians' experiences of students and reflections on their education have led to the view that undergraduate courses have to change. Medical schools need to produce competent doctors who enjoy medicine, want to take responsibility for their professional development, are able to adapt and change, and can cope with uncertainty. Problembased learning is an educational method which, at the very least, is enjoyable for the students, and may help to achieve these longer-term aims.

\section{Problem-based learning and the 21st century}

The course at Manchester is still in its infancy, as the first wave of students has just reached the final year of its training. Most of them will qualify in 1999 but will only become fully registered medical practitioners in the year 2000. It is to be hoped that these young doctors will be equipped for a lifetime of learning, that they will be able to adapt to change and know how to tackle difficult problems. From a psychiatric perspective, these young doctors will have a greater understanding of the relationship between physical, psychological and social aspects of disease, and will have acquired an ability to recognise and manage emotional distress in the patients that they see, not just those with overt mental illness.

\section{References}

Albanese, M. A. \& Mitchell, S. (1993) Problem-based learning: a review of literature on its outcomes and implementation issues. Academic Medicine, 68, 52-81.

Berkson, L. (1993) Problem-based learning: have the expectations been met? Academic Medicine, 68 (suppl.), S79-S88.

David, T. J. \& Patel, L. (1995) Adult learning theory, problem based learning, and paediatrics. Archives of Disease in Childhood, 73, 357-363.

General Medical Council (1993) Tomorrow's Doctors; Recommendations on Undergraduate Medical Education. London: GMC.

Kaufman, D. M. \& Mann, K. V. (1998) Comparing achievement on the Medical Council of Canada Qualifying Examination Part I of students in conventional and problem-based learning curricula. Academic Medicine, 73, 1211-1213.

Schmidt, H. G., Machiels-Bongaerts, M., Hermans, H., et al (1996) The development of diagnostic competence: comparison of a problem-based, an integrated, and a conventional medical curriculum. Academic Medicine, 71, 658-664.

Singh, S. P., Baxter, H., Standen, P., et al (1998) Changing the attitudes of 'tomorrow's doctors' towards mental illness and psychiatry: a comparison of two teaching methods. Medical Education, 32, 115-120.

Sharpe, M., Guthrie, E., Peveler, R., et al (1996) The psychological care of medical patients. Journal of the Royal College of Physicians, 30, 202-204.

Tosteson, D. C. (1990) New pathways in general medical education. New England Journal of Medicine, 322, 234-238.

Vernon, D. T. A. \& Blake, R. L. (1993) Does problem-based learning work? A meta-analysis of evaluative research. Academic Medicine, 68, 551-563.

Williams, C., Milton, J., Strickland, P., et al (1997) Impact of medical school teaching on pre-registration house officers' confidence in assessing and managing common psychological morbidity: three centre study. British Medical Journal, 315, 917-918.

\section{Further information}

The University of Maastricht and McMaster University at Hamilton, Ontario, both run short (13 week) workshops on various aspects of problembased learning as applied to medicine. The University of Maastricht also runs a distance learning Master's Programme in Health Professions Education - details available from: Office for International Relations, Faculty of Medicine, University of Maastricht, POB 616, 6200 MD Maastricht, Netherlands.

\section{Multiple choice questions}

1. Key universities responsible for the introduction of PBL undergraduate medical curricula include:

a Maastricht

b Newcasle, South Wales 

c Harvard
d McMaster
e Manchester.

2. The 'eight-step' learning process includes the following stages:
a clarification of terms and concepts that are unfamiliar
b formulation of learning goals
c self-study
d discussion of findings with other students at a subsequent tutorial
e asking the tutor for a tutorial on a particular aspect of the case.

3. The evaluation of PBL learning in comparison with lecture-based courses:

a is difficult to conduct in the context of medical undergraduate training because of contamination effects

$b$ has shown that PBL is superior with respect to students' performance on tests of factual knowledge

c has shown that PBL students perform significantly better in psychiatry

d has shown a clear advantage for PBL on all aspects of medical undergraduate training

$e$ has shown that PBL is very unpopular with students.

\section{On PBL courses:}

a students learn about medicine in an integrated fashion

b subjects such as anatomy and physiology are taught separately

c students are encouraged to learn as many facts as possible

d students are introduced to clinical concepts by the study of clinical cases

e students are encouraged to develop responsibility for their own learning.
5. In relation to the study of mental illness:

a aspects of psychological functioning can be built into any PBL case

b students have to learn about mental and physical illnesses together

c PBL is effective in making students' attitudes to psychiatry more positive

d PBL encourages students to think about psychiatry in a compartmentalised way

e somatisation and 'psychological conditions in the medically ill' can be easily integrated into cases which deal predominantly with medical or surgical problems.

\begin{tabular}{|c|c|c|c|c|}
\hline \multicolumn{5}{|c|}{ MCQ answers } \\
\hline 1 & 2 & 3 & 4 & 5 \\
\hline a $T$ & a $T$ & a $T$ & a $T$ & a $T$ \\
\hline b $\mathbf{T}$ & b $\mathrm{T}$ & b F & b $F$ & b $\mathrm{T}$ \\
\hline c $\mathrm{T}$ & c $\mathrm{T}$ & c $\mathrm{T}$ & c $\mathrm{F}$ & c $\mathrm{T}$ \\
\hline d $\mathrm{T}$ & d $\mathbf{T}$ & d F & d $T$ & d F \\
\hline e $T$ & e F & e $F$ & e $T$ & e $T$ \\
\hline
\end{tabular}

